\title{
Name Code Modified Text
}

National Cancer Institute

\section{Source}

National Cancer Institute. Name Code Modified Text. NCI Thesaurus. Code C93601.

A character string that is a revision of the original text to enable the coding of the text. 